\title{
Large-Scale Learning for Local Change: The Challenge of MOOCs as Educator Professional Learning
}

\author{
Joshua Littenberg-Tobiasa,b,*, Rachel Slama ${ }^{a, 1}$, Justin Reich ${ }^{a, c}$ \\ ${ }^{a}$ Massachusetts Institute of Technology \\ ${ }^{b}$ Massachusetts Institute of Technology \\ ${ }^{c}$ Massachusetts Institute of Technology
}

\begin{abstract}
How can large-scale online learning serve professionals' learning needs which are often highly localized? In this mixed-methods study, we examine this question through studying the learning experiences of participants in four massive open online courses (MOOCs) that we developed on educational change leadership $(\mathrm{N}=1,712)$. We observed that participants were able to integrate their learning from the online courses across a variety of settings. We argue that a key factor in this process was that the design of online courses was attentive to the various levels in which participants processed and applied their learning. We therefore propose the "Content-Collaboration-Context" model ("C-C-C") as a framework for designing and researching open online learning experiences for professional learning settings where participants' work is highly localized. In analyzing learner experiences in our MOOCs, we apply this framework to illustrate how individuals integrated the generalized content of the online courses into their context-specific practices. We conclude with implications for the design and research on online professional learning experiences.
\end{abstract}

Keywords: professional learning, online learning, large-scale learning environments

\section{Introduction}

Over the last decade, massive open online courses (MOOCs) have become an important part of the online learning landscape. However, with falling enrollments and challenges to their business model, many MOOC providers began developing new online-based professional degree and credential programs [1]. This shift also reflects a move away from content-based courses toward job-embedded professional learning with an emphasis on applying knowledge to real-world problems [2].

One potential area for growth for MOOCs are developing professional learning courses for educators. Professional educators make up a large portion of total MOOCs users and

\footnotetext{
*I am corresponding author

Email addresses: jltobias@mit.edu (Joshua Littenberg-Tobias), rslama@mit.edu (Rachel Slama), jreich@mit.edu (Justin Reich)
} 
often enroll in non-educator specific courses as forms of professional learning [3, 4]. Although the concept of developing MOOCs as professional learning for educators has been around for nearly a decade [5], recently, major research institutions have begun offering free or low-cost professional learning for educators with certificate and credentialing options. For example, the Friday Institute at North Carolina State University has developed a set of MOOCs for educators which have been used by over 40,000 users and highlighted by the U.S. Institute of Education Science (IES) as an innovative form of professional learning for teachers [6].

Yet, one of the challenges of creating MOOCs for educators is that although the content of MOOC is intended for large-scale populations, the work of educators is highly contextual. It can be difficult, and potentially unwise, for educators to directly apply ideas and concepts from experts to their own practice without being attentive the unique needs and characteristics of their own students $[7,8]$. Furthermore, the global, large-scale nature of MOOC learning must be reconciled with the wealth of empirical evidence that finds that teachers best improve their practice when learning with others in their school context $[9,10,11]$. Thus, the main dilemma that we address in this paper is how to make learning in a MOOC, which is global and decontextualized, relevant for the highly contextual and situational nature of teacher professional learning.

In this study, we explore this dilemma through the example of four educator professional learning MOOCs we developed on educational change leadership. These four MOOCs had 1,712 active participants in six course instances over an 18-month period. The design of these MOOCs were informed by a conceptual framework which we describe as the "ContentCollaboration-Context" model ("C-C-C"). Using this framework, we explore the extent to which participants changed their practices after taking these MOOCs. We also examine whether the learning design of the courses aided participants in integrating the generalized ideas and concepts from the MOOCs into their specific contexts.

\section{Background}

\subsection{The Importance of Local Context in Educator Professional Learning}

U.S. teachers and schools invest significant time and resources on professional learning. One study found that districts spend an estimated $1 \%$ to $6 \%$ of their budgets professional learning activities for teachers [12]. Researchers have identified many characteristics of effective educator professional learning related to its content and opportunities for collaboration. Namely, researchers have determined that effective professional learning is active, skill-based, linked to curriculum and school and district goals, intensive, and done in collaboration with others in their context $[13,9,14,15,11]$. Causal evaluations of professional learning that included these elements have found meaningful improvements in teacher practice and student learning $[16,17,18]$.

Some researchers have critiqued this literature for not paying enough attention to variation in outcomes, specifically, the role that context plays in the relationship between teacher learning, changes in instruction, and improvements in student outcomes [19, 20]. Educators, like other professionals, learn through observing and applying ideas within their own work setting [21]. As a result, the effectiveness of a professional learning experience often can 
vary substantially based on the context it which occurs [19, 11]. Educators who work in a context with supportive and effective colleagues are more likely to learn and shift their practices toward instruction that increases student learning. For example, in a study based on nearly a decade's worth of archival test scores and demographic data, Kraft and Papay [10] found that teachers in more supportive contexts (as measured by a statewide teacher surveys of professional learning context) improved more over time compared to their peers working in less supportive contexts. Over a period of ten years, teachers working in schools rated at the 75 th percentile of professional environment improved $38 \%$ more than teachers in schools at the 25th percentile. The instructional practices of other teachers in the school can also influence improvements in teaching. In a longitudinal study of a large urban U.S school district, Loeb, Kalogrides, and Béteille [22] found that teachers who worked in schools that were previously more effective at raising student achievement had greater growth in performance themselves than those working schools that were less effective at raising student achievement.

\subsection{Online Modalities Offer New Possibilities and Challenges for Teacher Professional Learning}

The field of online professional learning for educators has expanded greatly in the past two decades as new technologies emerge and social practices around those technologies evolve $[23,24]$. Online professional learning for educators - whether through online courses [25], learning networks $[26,27]$, or small independent groups [28] connects educators across varied school contexts. However, the research literature on online professional learning has been divided between, on one side, a focus on evaluating the effectiveness of formal online professional learning experiences designed for educators in specific context [29, 30, 25] and, on the other side, understanding how learners apply their learning from generalized informal online settings in their own contexts $[31,26]$. There has not been the same attention paid to online learning experiences, such as MOOCs, that are faced with the challenge of developing generalized content that can be implemented at a large-scale, but are also flexible enough that educators can integrate their learning within their specific context.

The limited previous research on MOOCs for educators has found some evidence that educators do integrate their learning into their practice. For example, Brennan, Blum-Smith, and Yurkofsky [32] studied participant learning in a MOOC-based online workshop designed to support K-12 teachers teaching Scratch, the open online programming environment for young people to create their own games, animations, and stories. They found that teachers reported the activity, peers, culture, and as relevance being most salient to their learning. Similarly, Avineri et al. [33] examined a set of MOOCs designed for U.S.-based K-5 math teachers designed by the Friday Institute at North Carolina State University. They found that elements in the courses triggered changes in practices, particularly the case study videos of instructions and interactive tools in the courses. Focusing on an international audience, Laurillard [34] developed and studied a MOOC for educators on the use of information and communication technology (ICT) in primary education that attracted educators from 174 countries. The study found evidence that participants planned to continue to apply what they had learned in their instruction. 
However, there has been limited theorizing in the online educator professional learning literature on how to design learning in MOOCs for educators so that it is effective for the contextual and situational nature of teaching. This dilemma does not just affect MOOCs for educators; but is arguable a challenge for all online learning models that seeks to provide job-embedded professional learning training across a variety of contexts [2]. For example, designers of a MOOC for business managers might face the same dilemmas of how to support participants in translating general management principles to the specific circumstances in learners' work contexts. In the next section, we propose a conceptual framework for designing and researching MOOCs for educators, and other large-scale job-embedded professional learning environments, that links the content of the course with integration into practice.

2.3. Content, Collaboration, and Context: A Framework for Examining Global Learning for Local Change

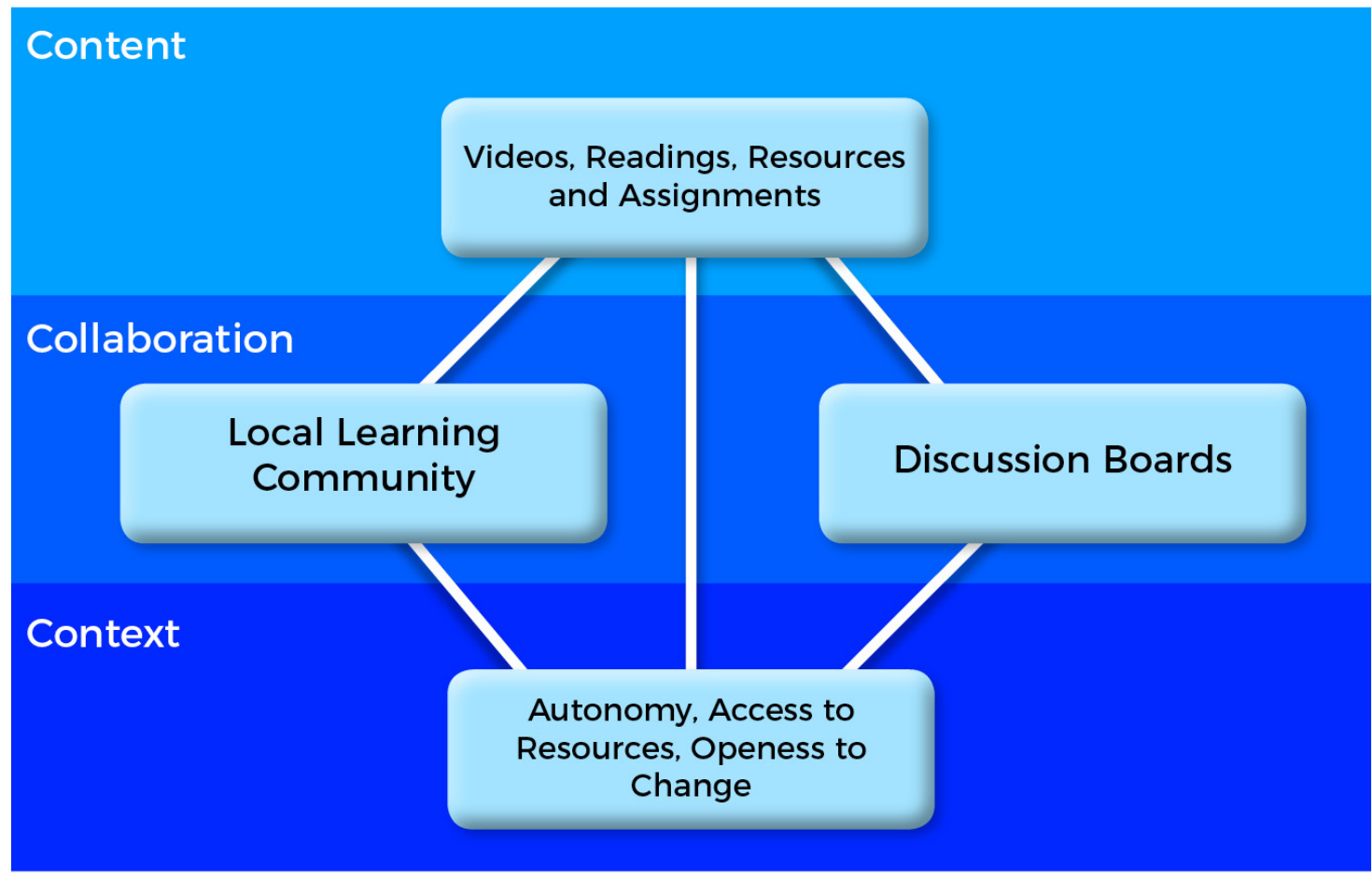

Figure 1: Conceptual Model for Educator Learning in MOOCs

We argue that the instructional design of large-scale professional learning environments need to be attentive to three levels of learning: content - the interaction between learners and the content provided by the instructional designers with the learning management software; collaboration - the interactions that participants have with others around the content 
(either in-person or online) through working together, comparing experiences, and sharing resources; and context - the workplace setting where participants apply their learning.

We therefore propose the "Content-Collaboration-Context" model ("C-C-C") (Figure 1), Within the model, the levels interact with one another; what and how participants learn within each level is filtered through their experiences at the other levels. For example, the content of the courses can stimulate interactions within online communities such as discussion forums as well as in local learning communities through sharing ideas and resources from the course with colleagues. Additionally, learning about others' practice can promote reflection on one's own context and local learning community. Finally all of these components are filtered within the specific supports and constraints of educators' own context before they result in changes in practice. This model situates educators' learning as an interaction between various levels that influence learning. As a result, it is aligned with complexity theory approaches to educator learning that emphasize interactions between complex systems that influence educator learning $[35,20,36]$.

\section{Current Study}

In this study, we investigate participating learning in four MOOC for educators through the "C-C-C" model to better understand how these environments can be designed to facilitate the transfer from large-scale online learning to local, contextualized practice. By mapping educator learning in these MOOCs to this framework, we will provide evidence about the utility of this framework for designing and researching powerful learning experiences for educators and other professionals.

We address the following research questions:

1. How did participants integrate the content of the course into their practice?

2. How did participants collaborate and share with others in both virtual and local contexts? To what extent were different forms of collaboration/sharing related to changes in practice?

3. How did variation in participants' local school context relate to how participants chose to collaborate with others and to changes in practices?

\section{Methods}

\subsection{Description of Courses}

The setting of this study were a set of four different MOOCs focused on change-leadership for educators - the principles of how to create change within messy conditions of schools [37]. Drawing on constructivist approaches to situated learning [38, 39], these online courses integrated learning into practice by supporting, challenging, and inspiring participants to take new insights from online learning and apply them directly to their instructional or leadership practices. The courses were administered over an eighteen month period from January 2018 to June 2019. Two of four courses were offered twice during this period so there were six total course "instances" during this time period. We describe the contents of each individual course below (using pseudonyms for blinding purposes): 
- Change Leadership for Innovation in Schools was a fourteen-week course focused on preparing leaders at all levels, teachers, principals, superintendents, for the challenge of leading innovation in schools. This course was offered in Fall 2018.

- Introduction to Design Thinking for Educators was a six-week course where learners were introduced to the concept of design thinking - a systematic approach to solving complex problems through iterative cycles of discovery, imagining, prototyping, testing, reflecting, and evaluating. This course was offered in both Spring 2018 and Spring 2019.

- Developing a Graduate Profile for Your School was a four-week course focused on supporting participants in developing a graduate profile, a shareable document that conveys what high school graduates in their community should know and be able to do. This course was offered in both Spring 2018 and Spring 2019.

- Introduction to Competency-Based Education was an eight-week course introduced participants to competency-based education (CBE), explained why schools might pursue it, and the opportunities and challenges educators and others face when implementing it. This course was offered in Spring 2019.

All courses were created by the same instructional design team, which included one of the authors of this paper, and used a similar pedagogical approach. The courses were designed around the concept of practical inquiry where learners engage in cycles of exploration, integration, and resolution [40]. Most units begin with instructor videos which were used to introduce key concepts and vocabulary. Case study videos highlighted applied examples of these concepts by interviewing practitioners in schools. Readings, activities, and links to resources provided opportunities for participants to extend their learning beyond the videos to deeper engagement with the content. Finally, assignments were structured around having learners apply their learning in their context. Participants might be asked to collect data or experiment with a form of instruction and then reflect on the experience. The instructional design team set up systems to encourage participants to share this work within the course forums and provide structured feedback to other participants on their assignments.

The instructional design team also provided support for participants to take the course with other participants in their context. Participants were encouraged to form "learning circles" which were learning communities where participants could discuss the content of the courses and reflect on how they might apply their learning within their school or organization. To support the formation of the learning circles, the instructional designers created facilitators' guides which contained tips for organizing and maintaining learning circles, suggested schedules and agendas for meetings throughout the course, questions to prompt discussions about course content, and strategies for making assignments and activities more collaborative. Course-designers also developed downloadable versions of course resources, sometimes called "take-out" packages to facilitate the sharing of course resources 


\subsection{Sample and Data Collection}

We used an integrative mixed-methods approach to our research design [41]. For our quantitative data, pre- and post-course surveys were integrated into the survey platform in both courses. Response rates for the pre-survey for participants in analysis sample were $91 \%$ and $51 \%$ on the post-survey. Survey links were emailed participants in the analysis sample $(\mathrm{N}=1,712)$ four to eight months after their respective course ended. Overall, $30 \%$ of participants in the analysis sample responded to the follow-up survey. Participants were included in the analytic sample if they either a) completed the course (which is defined as having earned at least $60 \%$ of the available points on course assignments) or b) spent at least one hour in the course platform. Additionally, we limited the analysis sample to participants who had at least partially completed a pre- or post-course survey. The analysis sample was internationally diverse. Although the plurality of participants were from North America (49\%), there were participants from all over the globe including South America (12\%), Africa (5\%), and Asia (18\%) (Table 1).

Table 1: Demographic Composition By Course (All Registrants and Analytic Sample)

\begin{tabular}{lcc}
\hline \hline & Non-Analysis Sample & Analysis Sample \\
\hline $\mathrm{N}$ & 26,546 & 1,712 \\
Female & $47 \%$ & $54 \%$ \\
Male & $53 \%$ & $46 \%$ \\
No Bachelor's & $14 \%$ & $6 \%$ \\
Bachelor's Degree & $33 \%$ & $27 \%$ \\
Master's or Professional Degree & $45 \%$ & $57 \%$ \\
Doctoral Degree & $7 \%$ & $11 \%$ \\
Africa & $5 \%$ & $5 \%$ \\
Asia & $28 \%$ & $18 \%$ \\
Europe & $20 \%$ & $14 \%$ \\
North America & $33 \%$ & $49 \%$ \\
Oceania & $2 \%$ & $3 \%$ \\
South America & $11 \%$ & $12 \%$ \\
Mean Age & 37 & 42 \\
\hline
\end{tabular}

We also conducted interviews with a stratified random sample of participants in each of the four courses, over-sampling for participants currently working in K-12 schools $(\mathrm{N}=35)$. Interviews were conducted over the phone or video chat using a semi-structured interview protocol. The content of the interview focused on their current school context, motivations for taking the course, and current or planned future actions based on what they learned in the course. All participants were interviewed at least once during the course. In two of the courses, Developing a Graduate Profile for Your School and Introduction to Design Thinking in Education, participants were also interviewed four to six weeks after the courses were completed. From these 35 cases we selected six to include as vignettes in our findings. 
A description of the participants in the vignettes is included in the Supplemental Tables (A.4).

\subsection{Measures}

\subsubsection{Course-Related Practices}

We developed scales of course-related practices for each course, and measured them on the pre, post, and follow-up surveys. Descriptive statistics, and reliability for each scales can be found in Supplemental Tables (Tables A.1 A.2). Outcomes variables were standardized using the pre-course survey mean and standard deviation for each course to allow comparisons across courses.

\subsubsection{Collaboration Indicators}

We measured collaboration using four indicators: participation in learning circles, sharing of course resources, downloading the facilitator's guide, and participating in the online forums. We measured learning circle participation $(\mathrm{N}=1,126)$ and sharing of course resources $(\mathrm{N}=376)$ using self-reported data from the course surveys. We used log data from the courses to determine which participants had downloaded the facilitator's guide or posted in the course forums $(\mathrm{N}=1,712)$.

\subsubsection{Context Indicators}

We measured educators' school contexts using both self-reported and publicly available data. To assess participants' perceptions of their school's instructional context, we administered a 6-item scale that measured respondents' attitudes toward the instructional culture in their school (e.g., "Faculty share a common vision of quality teaching and learning'). The survey item was administered on the pre-survey, only to participants who identified as K-12 educators ( $\mathrm{N}=326, \alpha=0.85$ ) (See Table A.3 in the Supplemental Tables). We also administered a question on the pre-survey about the socio-economic characteristics of the students in participants' schools. Socio-economic characteristics of students are often good proxies for the resource level of the school [42], academic achievement [43] and school climate [44]. Using an item from the 2011 Trends in International Mathematics and Science Study [45], we asked participants to report the percentage of students who were economically disadvantaged on a scale on a scale of $1(0 \%-10 \%)$ to 4 (More than $50 \%)(\mathrm{N}=436)$. Additionally, for educators in the U.S. we used information collected about participants schools on the pre-survey to match their school to National Center for Education Statistics (NCES) data on that school from the 2015-16 school year $(\mathrm{N}=140)$. In the U.S., the economic characteristics of students in the school is based eligibility for a free or subsidized lunch program. Students are eligible for a free lunch if they have family incomes at or below $130 \%$ of the poverty level and a reduced priced lunch if their family's income is between $130 \%$ to $185 \%$ of the poverty level [46].

\subsubsection{Demographic Variables}

We used demographic variables in all of our analyses as statistical controls. All participants are asked to fill out a brief demographic survey when signing up for the courses. The 
survey included questions about their age, gender, level of education, and country. Additionally, the server records the modal IP address of each participant when they are taking the course which allows for identification of user's continent. We supplemented this data with demographic information from the pre-course survey when there was no data available from the course platform.

\subsection{Analysis Methods}

We organize the description of mixed-methods analysis by research question. In cases where we repeat the same analysis procedure across multiple research questions, we refer back to previous research questions.

\subsubsection{Research Question 1}

To contextualize the changes in practices we found in the quantitative data we developed six short vignettes from the sample of participants who we interviewed. The vignettes drew on quotes from the interviews as well as forum responses and open-text from pre, post, and follow-up survey.

To model changes in practices, we used a hierarchical linear growth model (HLM) [47] to measure changes in practices across the pre, post, and follow-up survey. One benefit of using this type model is that it allows observations to be included in the model even if they do not have full data for all time-points. We chose to model time-points as a categorical variable in order to account for non-linearity in changes in participants' practices. The level-1 model is expressed in equation 1

$$
Y_{i j}=\pi_{0 i}+\pi_{1 i}(\text { Post })_{i}+\pi_{2 i}(\text { Followup })_{i}+e_{t i}
$$

Demographic covariates were added to the model for the intercept to adjust for differences in the pre-survey (2).

$$
\pi_{0 i}=\beta_{00}+\beta_{01}(\text { Male })_{j}+\beta_{02}(\text { Age })_{j}+\beta_{03}(\text { Age })_{j}+\beta_{04}(\text { Education })_{j}+\beta_{05}(\text { Continent })_{j}+r_{0 j}
$$

All analyses were conducted using the lmer function from the lme4 $\mathrm{R}$ package [48]. The full model results for all analyses can be found in the Supplemental Tables (A.5-A.6).

\subsubsection{Research Question 2}

We use the same model described in the previous question but added cross-level interaction terms to the slopes for the post and follow-up surveys for each of the collaboration indicators, running separate models for each term. The level-2 intercept and slopes models are represented in equations 3-4 (where $t$ represents time point).

$$
\begin{aligned}
\pi_{0 i} & =\beta_{00}+\beta_{01}(\text { CollaborationIndicator })_{j}+r_{0 j} \\
\pi_{t i} & =\beta_{t 0}+\beta_{t 1}(\text { CollaborationIndicator })_{j}+r_{t j}
\end{aligned}
$$




\subsubsection{Research Question 3}

We used the same approach for modeling the interaction with the school context indicators.

\section{Results}

5.1. The content provided multiple "hooks" to enable participants to successfully integrate the content of the course in their practice

In Research Question 1, we investigated the extent to which participants integrated the content of their course into their practice. We illustrate the possibility space of this question through the example of Dan, a participant in "Introduction to Competency-Based Education."

During the course, Dan worked for a district office of a large U.S-based school district where he was responsible for supporting teachers in developing Individualized Education Program (IEP) plans for students with special needs that documented the skills that students would need to learn to be successful after graduation. Previously, he reported struggling to find a way to help teachers meaningfully connect the state learning standards with the skills in the IEP plan: "We don't have a coherent map where we can look at the standards and identify how all of the skills within that standard are also represented across different standards."

Taking the MOOC changed how he approached his work with teachers. Dan began working departmental teams at various schools in the district to create a map, across grade levels and subjects, between the state learning standards and the skills students would be required to master. Dan reported that the process energized teachers in his district, promoting increased collaboration across departments and schools

It has gotten to this point where now I have two schools that have said I'm wondering how much more overlap we can create... So that school, their two teams started planning together in social studies and ELA. And another school, which is in our network was invited to participate....so I was just amazed at seeing that.

Like Dan, participants across the analysis sample reported changes in their use of practices related to the content of the courses (Figure 2). Compared to the pre-survey, participants reported higher prevalence of practices related to course-content on the post-survey. On average, participants increased their practices by 0.42 standard deviations $(p<0.001)$ above their pre-survey averages. Although there was a slight attenuation of the effect on the follow-up survey, the effect persisted 4-8 months after the course ended. Four to eight months after the course ended, participants reported 0.25 standard deviation higher levels of practices related to course content $(p<0.001)$.

The content of the courses offered multiple "hooks" that allowed participants across varied contexts to apply the generalized concepts of the course to specific problems from their own context. For example, Dan was able to connect an idea from one of the course 


\section{Course Practices}

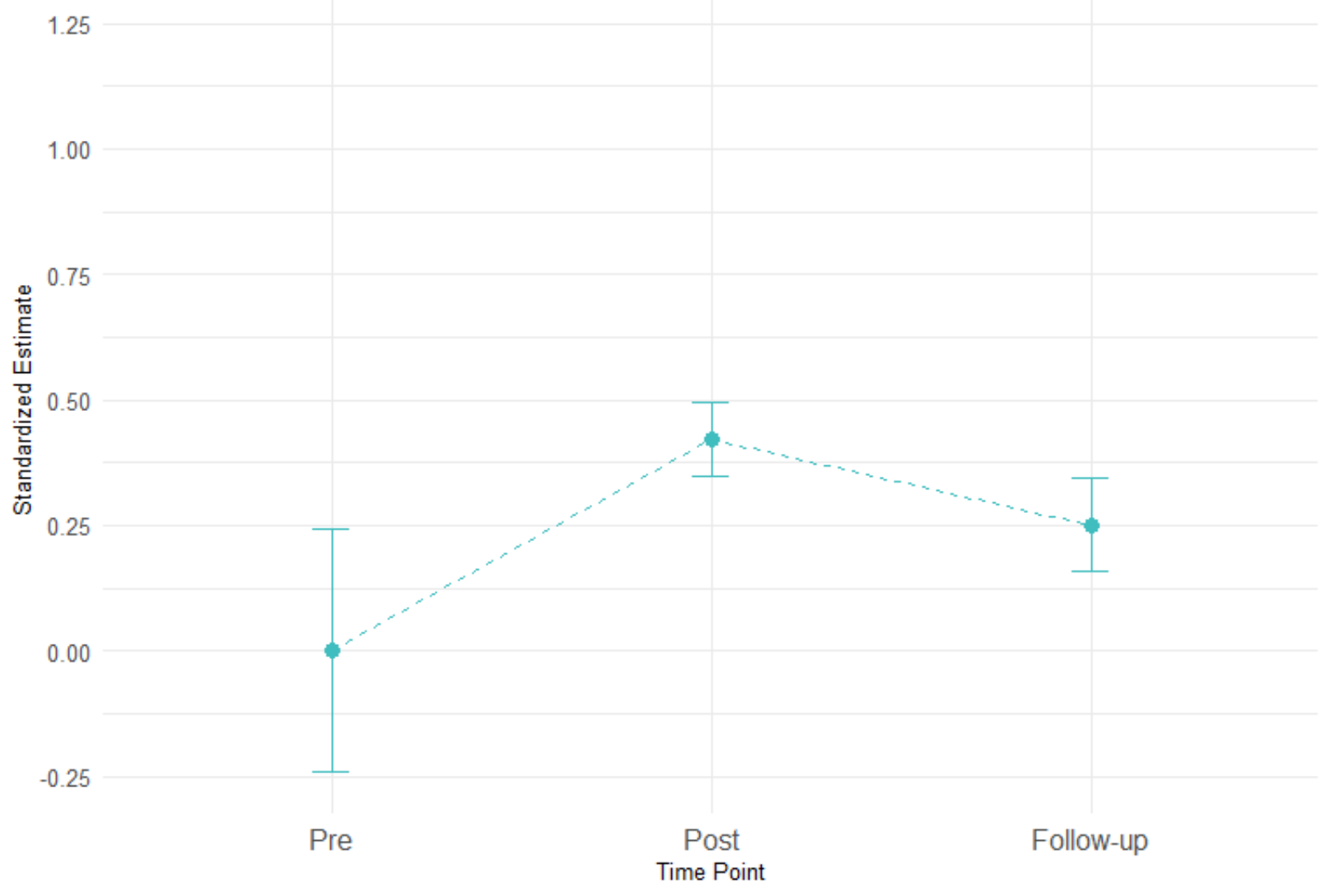

Figure 2: Estimated Change in Practices From Pre-Survey Average

videos to a specific problem he had observed in practice. Dan observed a segment of a course video was an "a-ha" moment which caused him to re-evaluate a part of his practice:

And in the video they made them reference, the two people made the reference towards standards and competencies and up to that point, I was interpreting them as pretty much the same...when I realized that oh, okay when you're making this reference to competencies it's to the knowledge and skills within these standards and how these skills can be represented across that. And so it also informed my understanding too that some places have a coherent map.

The actions that Dan ultimately took as a result, working with teachers to link skills across standards, was not directly prescribed in the course. However, the content of the course was flexible enough that educators like Dan could independently have "a-ha" moments that they could link the content of the course to specific parts of their own practice.

Participants also described how doing the assignments helped them understand how the ideas from the course might fit within their own practice within their local context. We illustrate this through the example of "Ann" a kindergarten teacher who described in an 
interview how a particular assignment in "Introduction to Design Thinking in Education." In the assignment, she was asked to use design thinking with her students which prompted her to think about broader shifts in her curriculum.

We do a unit on construction, so it kind of already fits in with the kindergarten curriculum that we use. Again, I kind of like the give back to the community aspect, which isn't part of our curriculum. I'd really try to go back and look into the language around that and how I could incorporate that method into my class.

Eight month later, on a follow-up survey, Ann reported that she had begun making broader changes to her curriculum.

I am seeking out more opportunities to engage in engineering. I am exploring novel engineering and maker mindset professional development courses...I have been able to incorporate some engineering and design and am hoping to implement more in the spring as it fits in with our curriculum,

Similar to Dan, the actions that Ann took were not directly built into the instructional design of the online course. However, by asking participants to make changes in their context the assignments may have prompted participants to extend their learning to other aspects of their practice based on what they learned in the course.

5.2. Collaboration was one mechanism through which people translated the content of the course into their own local context, but we did not find that changes in course practices varied by how participants collaborated with others

In Research Question 2, we examined the role of collaboration in translating learning the content from the courses into practice. In our analysis, we examined two main forms of collaboration around course content. The first, which we describe as "virtual collaboration", occurred between participants in the online course and was mainly clustered within the course forums. Based on log data, $79 \%$ of participants visited the forums and $52 \%$ of participants in the analysis sample posted at least once in the forums.

Participants used what they learned in the discussion forums about others' experiences to re-evaluate circumstances in their own context. "Beth", a participant in "Introduction to Competency-Based Education", was developing professional development for her U.S.-based school district around a large-scale learning initiative which was related to the content of the MOOC. Beth described how hearing about what other participants were doing in the forums, along with the school profile videos, were helpful in highlighting how difficult it would be to implement the initiative.

Just through reading and watching the videos and seeing the posts of what other people are doing, I think I've gained a much better understanding of what I would have to teach better with regards to competency-based education. [initiative]

At the end of the course, Beth reported that the course affected her practice was making her think more critically about how she approached this initiative: 
I used to think that it wouldn't be too difficult to implement competency-based education if we just had the right people willing to work hard, but now I think that there are many more layers to [it] than I previously considered and for full implementation to occur, much more expansive, strategic planning is needed.

Four months after the course ended, Beth reported the course changed the way she approached how she facilitated professional learning, "Information I share with teachers is more accurate and how we model PD is evolving." Learning from others in the forums helped Beth re-calibrate how she approached this new initiative with teachers in her district.

The second type of collaborating we observed was "local collaboration" where participants took their learning outside of the online course platform, by forming learning with others in their local context. In surveys, 37\% of participants reported that they either planned to or participated in a learning circle during the course. According to course log data, $11 \%$ of participants downloaded the facilitators guide for the course.

Another way participants collaborated with others in local context was by sharing materials from the online courses. Nearly seven in ten participants (68\%) reported sharing materials from the course with others in their school or organization. Of those who reported sharing content, the most common ways that participants reported sharing materials is through sharing content at in-person meetings (86\%), adapting the content of the course for use in a professional development setting (61\%), and integrating the course content into existing professional development offerings (51\%).

Participants adapted the learning from the course when collaborating and sharing with others in their local context. Amina was a Canadian high school teacher whose goal in taking the online course was to build her skills to better engage with the families of immigrant students in her school. During the course, Amina set-up meetings with parents in the community to help them understand how innovative practices might benefit their children. She credited the course with helping her develop the language around innovation, "I gained more knowledge about how to implant innovation in the classroom and better collaborate with the school."

Six months after completing the course, she reported developing workshops for educators about how they can implement change in their school.

I became a change leader in my community and in my school, [in] collaboration with the administration, parents and educators. I organized workshops on how other educators can implement change in their schools.

Through sharing with others, using the tools and resources she learned in the course, Amina was able to integrate her learning from the online courses into their practice in their local context. This also extended the reach of the course, enabling even those who did not take the online course to be exposed to the ideas and concepts from the course within their own local setting.

As part of Research Question 2, we also investigated the extent to which collaboration and sharing, both locally and virtually, was related to learners' changes in practices related to the content of the courses (Figure 3). Participants who formed learning circles (ES $=0.27$ 
$\mathrm{SD}, p<0.001)$ and shared resources in their context $(\mathrm{ES}=0.44 \mathrm{SD}, p<0.001)$ reported significantly higher levels practices on the pre-survey than those who did not. However, even though all participants made gains in practices on the post and follow-up survey, there were no significant differences in the rate at which participants changed their practices. Participants who reported participating in a learning circle did not report any meaningfully higher rates of changes in practices (ES Post $=-0.02 \mathrm{SD} p>0.1$, ES Follow-up $=0.001$ $\mathrm{SD}, p>0.1)$. Sharing resources was positively related to slightly higher rates of changing practices (ES Post $=0.08 \mathrm{SD} p>0.1$, ES Follow-up $=0.17 \mathrm{SD}, p>0.1$ ), but the estimates were not statistically significant. Additionally, we saw no meaningful differences in the rate of changes in practices by whether participants posted in the discussion forums (ES Post $=$ $0.06 \mathrm{SD} p>0.1$, ES Follow-up $=0.06 \mathrm{SD}, p>0.1$ ).

However, we did find that accessing the facilitator's guide was related to an increased rate of changes in practice, Participants who downloaded the facilitator's guide had significantly greater growth in practices on both the post $(\mathrm{ES}=0.30 \mathrm{SD}, p<0.01)$ and follow-up survey $(\mathrm{ES}=0.27 \mathrm{SD}, p<0.05)$. This suggests that making resources available to support local collaboration may have contributed to changes in practice within participants' local contexts.

Learning Circle

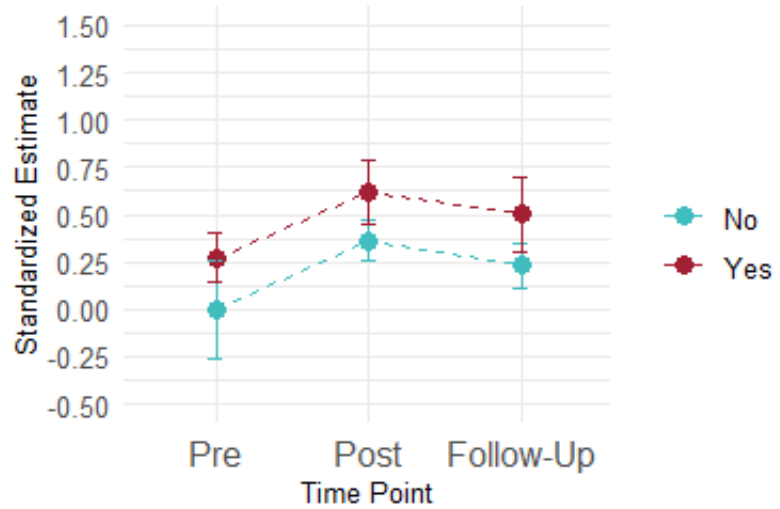

Posted in Forums

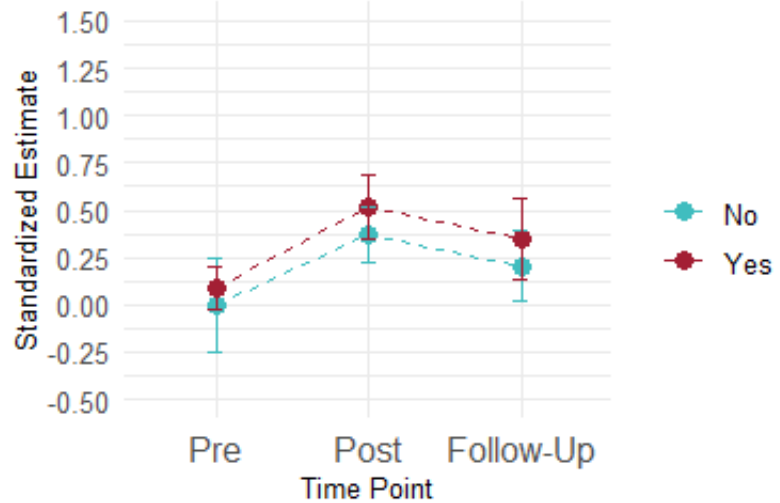

\section{Facilitator's Guide}

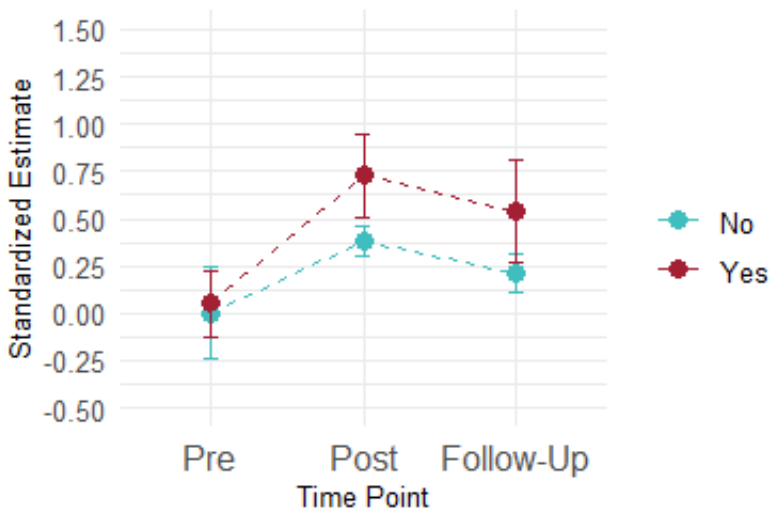

Shared Resources

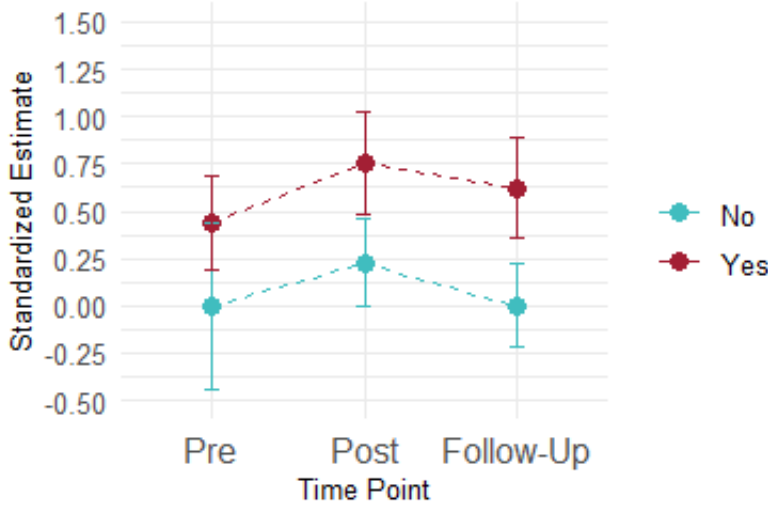

Figure 3: Estimated Changes in Practices From Pre-Survey Average By Collaboration Activity 
5.3. Context was a factor in how participants applied their learning in practice but it was not a determinant factor in how much participants changed their practices

In Research Question 3, we examine how local school contexts were related to how participants applied their learning in practice. To explore this question, we use the contrasting examples of "Danielle" and "Alexis" who were U.S.-based high school teachers who participated in "Developing a Graduate Profile for Your School" Both approached the course with similar sets of motivations to change the culture of instruction at their respective schools. Danielle was concerned that instruction in her school was overly focused on standardized testing, observing that "so as far as academic content, it's really focused on making sure that the kids are ready for the test, unfortunately." She found that this environment often undermined student motivation for learning, "the kids are just... They're really not excited about being there and the work that they do." Alexis similarly found her colleagues' instruction lacking in student engagement, "this school, the majority of teachers still do direct instruction. They stand up. They teach. They do the book and answer questions. That's it."

However, the local contexts that they worked in differed substantially. The school where Danielle worked was a large, racially diverse public school. Danielle was the only person in her school taking the course at the time it was being offered. For Danielle, participating in course widened the gulf between her own views on education and those of her colleagues in her school. In her interview, she described her evolution this way:

I kind of thought before taking the course, I was kind of thinking that every teacher on campus kind of has an idea of what graduates should know and be able to do, and then they're incorporating that into their lessons, because it was always important to me to make sure that we were creating good citizens. So I kind of thought that was in every teacher's mindset when they were planning their lessons. But as I've been talking to people, they were just kind of focusing on academic content, and not really thinking about what we want the humans to be able to do beyond academics.

Participating in the online course helped her critically examine her school's approach to instruction and develop a plan to take action to address those concerns. Danielle successfully convinced her administration to change her schedule so she could spend more time providing extra support to students to make sure they stay on track. By taking individual steps to better support students, she was able to begin the process of transforming her own teaching practice.

In contrast, "Alexis", worked at a private school with fewer constraints and access to more resources. Alexis was also able to organize a learning circle for teachers and administrators at her school to work on the course together. Her goal with the learning circle was to integrate the concept of a graduate profile from the online course into her school's strategic plan. She observed that "my goals are to help us create a cohesive profile that allows us and articulates the need to move the faculty forward."

Using ideas she learned in the online course, Alexis and the colleagues in her learning circle organized a three-day workshop for faculty in her school. She and her colleagues also 
encouraged their school to create graduate profiles for faculty and administrators in addition to students. She observed that ideas from the course had become part of the culture at her school.

That profile process is really good for us, going through it, because we're now using it to create a common language across the entire school. In how we talk about things, how we interact with each other, how we look at the characteristics of what we want in people we work with and work around.

Although Danielle and Alexis both had the same goal of shifting instructional practices in their school, how they integrated what they learned from the online courses differed based on factors in their local context. Because Danielle worked in a school with fewer resources and opportunities for collaboration, the changes she chose to make focused more on changes to her own teaching practice. Alexis, by comparison, had greater access to resources, the support of the school administration, and had colleagues who she could collaborate with on the course. As a result, she was able to begin to make more systemic changes to her school's instructional culture.

Throughout the analysis sample, we observed this variation in school contexts. For example, there were substantial numbers of participants who reported working in schools where less than one-tenth of the students were economically disadvantaged (40\%) and there were also substantial numbers of participants who reported working in schools where more than half of the students were economically disadvantaged (23\%).

We found similar variation in student demographics when we linked to publicly-available data. For participants in our U.S. public schools we were able to link to public records about the percent of students eligible for free or reduced price lunch, an indicator of economic disadvantage [49]. In our sample, the average proportion of students eligible for this program within participants' schools was $36 \%$ with a standard deviation of $27 \%$. This meant that a participant one standard deviation below the mean on this metric was working at school with very few economically disadvantaged students (9\%). In contrast, a participant one standard deviation above the mean on this metric worked at a school with more than half $(63 \%)$ of the students coming from economically disadvantaged households.

Another way that educators' school contexts varied was in the school cultures around instruction, teacher leadership, and collaboration. On the pre-survey, participants were asked to answer questions, on a 1-6 scale, about their school cultures around instruction, teacher leadership, and collaboration which we averaged into a scale we termed "school instructional climate." Reported school instructional climate varied substantially between participants in the analysis sample; the mean was 4.10 and the standard deviation was 0.90. Participants in schools one standard deviation below the mean reported much less supportive work environments than participants in schools one standard deviation above the mean (Table 2).

Based in part on the examples of Alexis and Danielle, we theorized participants in schools with fewer economically disadvantaged students and/or better instructional climates would also be more likely to collaborate with colleagues in their schools. We report the results from this analysis in Figure 4. For percentage eligible for free or reduced lunch and school 
Table 2: Percent Agree or Strongly Agree by School Instructional Climate Scale (Selected Items)

\begin{tabular}{lccc}
\hline \hline & $\begin{array}{c}\text { One SD } \\
\text { below mean } \\
(<-1.0)\end{array}$ & $\begin{array}{c}\text { Middle } \\
\text { Range } \\
(-1.0-1.0)\end{array}$ & $\begin{array}{c}\text { One SD } \\
\text { above mean } \\
(>1.0)\end{array}$ \\
\hline $\begin{array}{l}\text { Faculty share a common } \\
\text { vision of teaching and learning }\end{array}$ & $2 \%$ & $39 \%$ & $92 \%$ \\
$\begin{array}{l}\text { Faculty frequently work } \\
\text { together to solve school-wide } \\
\text { problems }\end{array}$ & $2 \%$ & $39 \%$ & $92 \%$ \\
$\begin{array}{l}\text { School leaders are open to } \\
\text { adopting innovative } \\
\text { instructional practices }\end{array}$ & $3 \%$ & $5 \%$ & $65 \%$ \\
\hline
\end{tabular}

instructional climate, we compared those one standard deviation above the mean to those one standard deviation below the mean. For the self-reported school economically disadvantaged indicator, we compared those working in school with $0 \%-10 \%$ economically disadvantaged to those in schools with more than $50 \%$ economically disadvantaged.

We found that having fewer economically disadvantaged students and better school instructional climate were related to higher levels of local collaboration. Participants were more likely to report participating in learning circles and sharing resources from the courses in schools with fewer economically disadvantaged students and better reported instructional climates. However, the opposite was true for virtual collaboration. Participants were more likely to post in the forums if they reported worse instructional climates in their schools, and for U.S. public school teachers, if they worked schools with more economically disadvantaged students.

These results are echoed by another finding from a question on the follow-up survey about learning circles. For participants who said they did not participate in a learning circle, we asked why they did not join one. The most common response, selected by $42 \%$ of participants, was that "there wasn't anyone in their school or organization who could take the course with them." This suggests that factors at the local level likely influenced to what extent participants collaborated with others in their local context.

As part of Research Question 3, we also examined whether school context was related to changes in practices. We plot the estimates from our model in Figure 5. Participants who reported high percentages of economically disadvantaged students (More than 50\%) in their schools had lower changes in practice than participants in schools with a low percentage of economically disadvantaged students (0\%-10\%) (ES $=-0.29 \mathrm{SD}, p<0.1)$ and smaller, but not statistically significant changes the on the follow-up survey ( $\mathrm{ES}=-0.14 \mathrm{SD}, p>0.1$ ). Among participants in U.S. public schools, for whom we had publicly available, we found that participants with more economically disadvantaged students had lower reported levels of practice on the pre-survey $(\mathrm{ES}=-0.15 \mathrm{SD}, p<0.1$ ), but there was no meaningful differences 

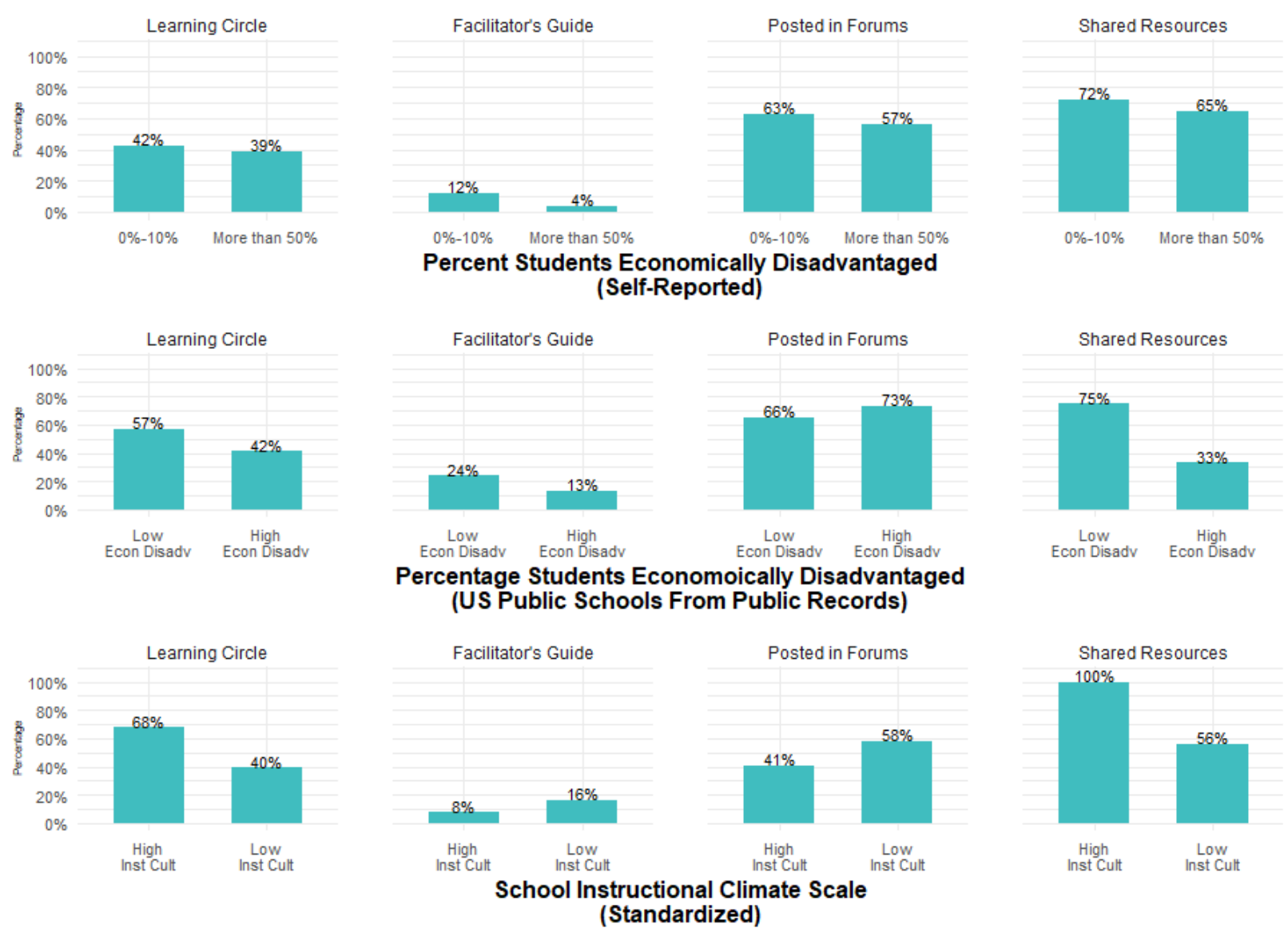

Figure 4: Participation in Local and Virtual Collaboration By School Demographics

in changes in practice (Post $\mathrm{ES}=0.08 \mathrm{SD}, p>0.1$, Follow-up $\mathrm{ES}=0.06 \mathrm{SD}, p>0.1$ ). Additionally, participants in schools with better school instructional cultures reported higher levels of course-related practices on the pre-survey ( $\mathrm{ES}=0.12 \mathrm{SD}, p<0.05)$. However there were no statistically significant differences in changes in practice on the post $(\mathrm{ES}=0.08 \mathrm{SD}$, $p>0.1$ ) or follow-up surveys ( $\mathrm{ES}=-0.01 \mathrm{SD}, p>0.1$ ).

These findings suggest that participants across a variety of contexts were able to identify ways of changing their practice after completing the online courses. Although context played a significant role in how participants interacted with course content and collaborated with others, as exemplified by the examples of Alexis and Danielle, the content was flexible enough that participants could find identify ways within their own context to change their practice. 


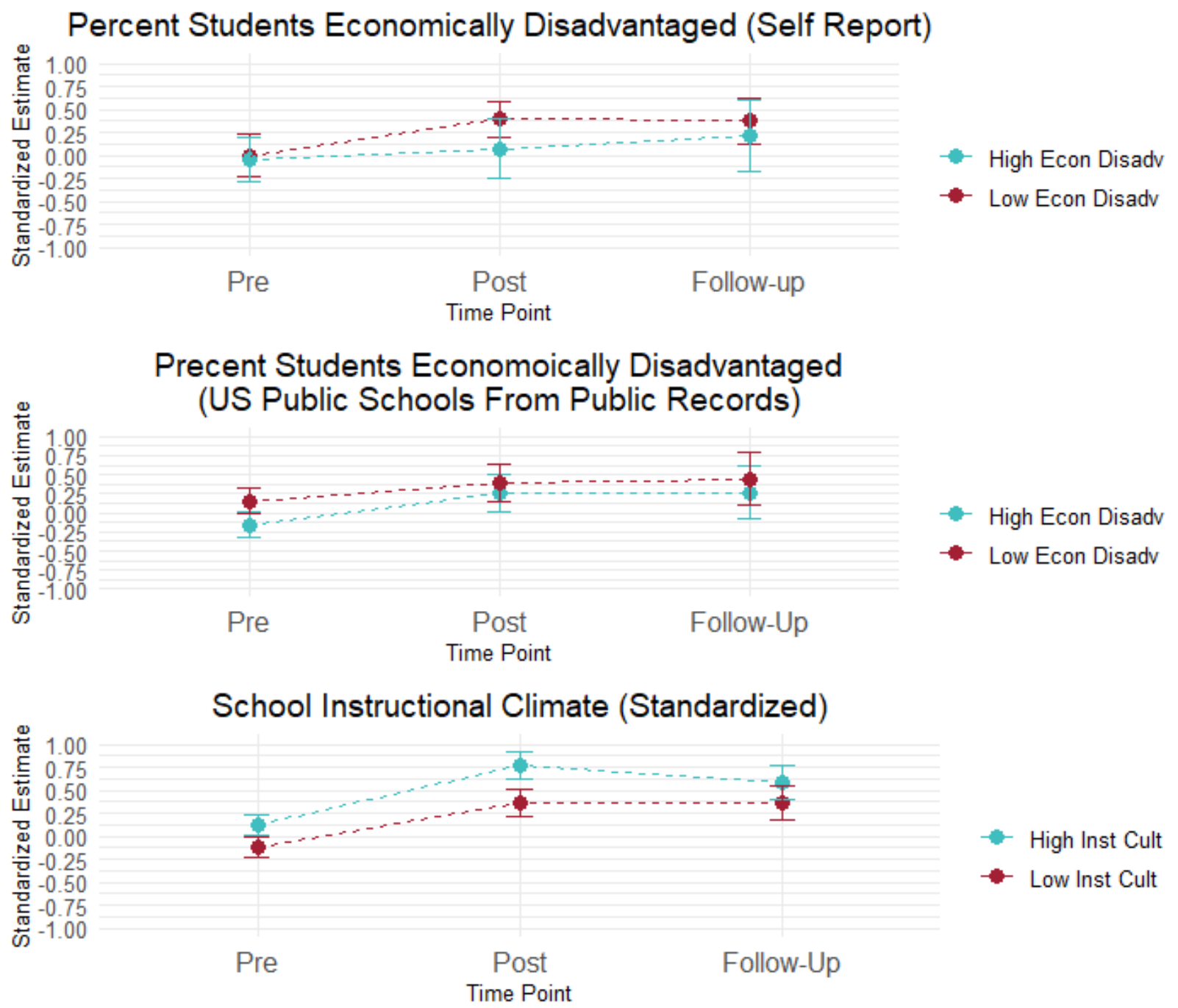

Figure 5: Estimated Change in Practices From Pre-Survey Average By Economically Disadvantaged Students and School Instructional Climate 


\section{Discussion}

As MOOC developers seek to develop more offerings targeted at learners looking for jobembedded professional learning, the question about how to design learning environments that work for users across different contexts will become increasingly relevant. We investigated this question through four MOOCs that we developed as professional learning courses for educators. The design of the courses were informed by attention to the different levels at which participants learn, which we summarized as the "Content-Collaboration-Context" ("C-C-C") model.

Our study found several promising components of designing courses with this model in mind. For participants in the courses we studied, the learning process within the online course was deeply intertwined with their own practice. Course content-lecture videos, video school case studies, and assignments - gave participants opportunities to integrate knowledge and practice. Because the content offered multiple "hooks" to practice, through assignments and videos, participants could choose how they would integrate the learning from the course into their practice. After the course, these ideas and concepts that participants came across in the videos and assignments later were integrated into their own professional practice.

Additionally, educators' context was only one of many contributing factors to changes in practices. Participants reported changes in practice across different types of contexts and we did not find strong evidence that context moderated changes in practice. One reason for this may be the courses provided enough flexibility so that participants could adjust how they interacted with the courses based on the limits and constraints of their context. For example, participants in schools with a higher percentage of students from economically disadvantaged backgrounds and worse school instructional climates were less likely to collaborate with others in their local context by joining learning circles or sharing resources. However, these participants were more likely to collaborate virtually with others on the course through the course discussion forums. Other researchers have found similar patterns, where educators make deliberate choices about how they engage with online content based on their specific contextual needs [50, 27].

These findings suggest that by including flexibility in design, instructional designers can potentially bridge the gap between the content intended for a large-scale audience and specificity of participants' local context. We believe the goal should not be to generate content that is applicable to every context; this would be quite difficult to accomplish in practice. Nor should instructional designers develop MOOC content that serves only a particular audience. Rather, we content that instructional designers should structure content so individuals have multiple, varied opportunities to integrate the knowledge and concepts from the course with their own specific understanding of their context.

The analysis also identified limits to how much we can link design elements in the courses with outcomes across varied context using the observational approach we employed in this study. Although we found qualitative evidence that participants found collaboration to be useful for their learning, in our quantitative analysis, we did not find meaningful differences in how much participants changed their practices for most of the collaboration indicators we examined. One potential issue we identified in the data was that the form of collaboration 
was highly contextual and participants' contexts were highly variable. As a result, context was likely an important confounding factor in these analyses. This constraint makes it difficult to correlate design features intended to foster collaboration with changes in practice.

Future research should further explore these types of connections. In subsequent work, we intend to expand on this current research and explore more deeply the connections between design features and integration into context. We will use experimental research designs to study the causal relationships between design features and changes in practices. The design of these studies will need to ensure fairness in access to learning resources across conditions while still being robust enough to study the impact of these features across varied contexts. Additionally, we will more deeply investigate how participants integrate their learning into their own contexts through ethnographic observation and site-based case studies. A limitation of this study is that we only included vignettes from participants in North America. In future studies, we will aim to incorporate a broader selection of participant experiences globally. Finally, we will aim to collect more detailed data about learning within the course through activities and open-ended reflection prompts that can help link content with changes in practices. Through these activities, we will build on the initial set of research findings to further elaborate and expand on the "C-C-C" model.

\section{Conclusion}

In this study, we addressed the dilemma of how to make the generalized content of MOOCs work across varied local contexts focusing on the example of educator professional learning. This study offers evidence that careful attention to content, collaboration, and context is important in designing and researching MOOCs that aim to provide job-embedded online learning for professionals across varied contexts. The evidence described in this study lays a foundation for many potential future uses in other online professional learning contexts where these questions will continue to emerge.

\section{Appendix A. Supplemental Tables}

Table A.1: Descriptive Statistics for Course-Related Practices

\begin{tabular}{ccccccc}
\hline \hline & \multicolumn{2}{c}{ Pre-Survey } & \multicolumn{2}{c}{ Post-Survey } & \multicolumn{2}{c}{ Follow-up Survey } \\
\hline Course Name & Mean & SD & Mean & SD & Mean & SD \\
\hline Intro to CBE & 2.95 & 0.83 & 3.14 & 0.74 & 2.88 & 0.88 \\
Change Leadership & 3.75 & 0.83 & 4.15 & 0.73 & 3.84 & 0.97 \\
Design Thinking & 2.56 & 1.04 & 3.5 & 0.86 & 3.38 & 0.94 \\
Graduate Profile & 3.69 & 0.94 & 3.96 & 0.74 & 3.89 & 0.9 \\
\hline
\end{tabular}


Table A.2: Reliability for Course-Related Practices

\begin{tabular}{ccccc}
\hline \hline Course Name & Num Items & Pre $\alpha$ & Post $\alpha$ & Follow-up $\alpha$ \\
\hline Intro to CBE* & 5 & 0.87 & 0.83 & 0.88 \\
Change Leadership & 4 & 0.86 & 0.88 & 0.90 \\
Design Thinking & 2 & 0.77 & 0.69 & 0.85 \\
Graduate Profile & 2 & 0.81 & 0.61 & 0.83 \\
\hline
\end{tabular}

${ }^{*}$ Competency-Based Education

Table A.3: Descriptive Statistics for School Instructional Culture Composite

\begin{tabular}{lcc}
\hline \hline Variable & Mean & SD \\
\hline $\begin{array}{l}\text { Faculty share a common vision of quality } \\
\text { teaching and learning }\end{array}$ & 4.02 & 1.26 \\
\hline $\begin{array}{l}\text { School leaders listen to a variety of } \\
\text { perspectives when making decisions }\end{array}$ & 4.00 & 1.29 \\
$\begin{array}{l}\text { Faculty frequently work together to address } \\
\text { school-wide problems }\end{array}$ & 3.95 & 1.19 \\
$\begin{array}{l}\text { When problems arise, faculty try address } \\
\text { the root cause of problems instead of } \\
\text { symptoms }\end{array}$ & 3.67 & 1.23 \\
$\begin{array}{l}\text { Faculty collect many different types of } \\
\text { student data to inform instruction. }\end{array}$ & 3.81 & 1.19 \\
$\begin{array}{l}\text { School leaders are open to adopting } \\
\text { innovative instructional practices }\end{array}$ & 4.40 & 1.24 \\
\hline
\end{tabular}


Table A.4: Course Participants Described in Vignettes

\begin{tabular}{|c|c|c|c|}
\hline Pseudonym & $\mathrm{RQ}$ & Course Name & Short Description \\
\hline Dan & 1 & Intro to $\mathrm{CBE}^{*}$ & $\begin{array}{l}\text { School district office employee } \\
\text { with a focus on helping teachers } \\
\text { support students with special } \\
\text { needs }\end{array}$ \\
\hline Ann & 1 & Design Thinking & $\begin{array}{l}\text { Kindergarten teacher interested } \\
\text { in incorporating design thinking } \\
\text { into the curriculum }\end{array}$ \\
\hline Beth & 2 & Intro to $\mathrm{CBE}^{*}$ & $\begin{array}{l}\text { School district office employee } \\
\text { responsible for developing } \\
\text { district-wide professional } \\
\text { learning }\end{array}$ \\
\hline Amina & 2 & Change Leadership & $\begin{array}{l}\text { High school teacher interested in } \\
\text { building relationships with } \\
\text { immigrant families }\end{array}$ \\
\hline Alexis & 3 & Graduate Profile & $\begin{array}{l}\text { High school teacher at a private } \\
\text { school interested in changing } \\
\text { school-wide instructional } \\
\text { practices }\end{array}$ \\
\hline Danielle & 3 & Graduate Profile & $\begin{array}{l}\text { High school teacher at urban } \\
\text { public school interested in } \\
\text { changing school-wide } \\
\text { instructional practice }\end{array}$ \\
\hline
\end{tabular}

*Competency-Based Education 
Table A.5: Models Results for RQ1 and RQ2

\begin{tabular}{|c|c|c|c|c|c|}
\hline & \multicolumn{5}{|c|}{ Dependent variable: Course-Related Practices (Standardized) } \\
\hline & $\begin{array}{l}\text { Time Only } \\
\text { (1) }\end{array}$ & $\begin{array}{c}\text { Learning Circle } \\
(2)\end{array}$ & $\begin{array}{c}\text { Facilitator's Guide } \\
\text { (3) }\end{array}$ & $\begin{array}{l}\text { Posted Forums } \\
\text { (4) }\end{array}$ & $\begin{array}{c}\text { Shared Resources } \\
(5)\end{array}$ \\
\hline$\overline{\text { Post }}$ & $0.42^{* * *}(0.04)$ & $0.36^{* * *}(0.06)$ & $0.38^{* * *}(0.04)$ & $0.37^{* * *}(0.08)$ & $0.23^{*}(0.12)$ \\
\hline Follow-up & $0.25 * * *(0.05)$ & $0.23 * * *(0.06)$ & $0.21 * * *(0.05)$ & $0.21^{* *}(0.09)$ & $0.001(0.11)$ \\
\hline Male & $-0.04(0.05)$ & $-0.04(0.06)$ & $-0.03(0.05)$ & $-0.03(0.05)$ & $-0.07(0.10)$ \\
\hline No Bachelor's & $-0.18(0.12)$ & $-0.10(0.14)$ & $-0.18(0.12)$ & $-0.16(0.12)$ & $-0.21(0.23)$ \\
\hline Master's & $0.0001(0.06)$ & $0.06(0.07)$ & $-0.001(0.06)$ & $0.003(0.06)$ & $-0.25^{* *}(0.12)$ \\
\hline Doctoral & $-0.001(0.10)$ & $0.04(0.11)$ & $-0.01(0.10)$ & $0.0005(0.10)$ & $-0.09(0.17)$ \\
\hline Age & $0.0005(0.003)$ & $0.001(0.003)$ & $0.0002(0.003)$ & $0.0002(0.003)$ & $0.0001(0.01)$ \\
\hline Age 2 & $-0.0001(0.0002)$ & $-0.0000(0.0002)$ & $-0.0001(0.0002)$ & $-0.0000(0.0002)$ & $-0.0002(0.0004)$ \\
\hline Africa & $-0.08(0.12)$ & $-0.05(0.12)$ & $-0.08(0.12)$ & $-0.07(0.12)$ & $-0.12(0.20)$ \\
\hline Asia & $0.01(0.07)$ & $-0.02(0.08)$ & $0.003(0.07)$ & $0.03(0.07)$ & $0.09(0.15)$ \\
\hline Europe & $-0.03(0.08)$ & $-0.06(0.09)$ & $-0.03(0.08)$ & $-0.01(0.08)$ & $-0.11(0.15)$ \\
\hline Oceania & $-0.08(0.17)$ & $-0.05(0.20)$ & $-0.07(0.17)$ & $-0.06(0.17)$ & $-0.41(0.37)$ \\
\hline South America & $0.12(0.08)$ & $0.14(0.09)$ & $0.11(0.08)$ & $0.13(0.08)$ & $0.22(0.15)$ \\
\hline Moderator & & $0.27^{* * *}(0.07)$ & $0.05(0.09)$ & $0.09(0.06)$ & $0.44^{* * *}(0.13)$ \\
\hline ModeratorXPost & & $-0.02(0.09)$ & $0.30^{* * *}(0.11)$ & $0.06(0.09)$ & $0.08(0.14)$ \\
\hline ModeratorXFollow-up & & $0.001(0.10)$ & $0.27^{* *}(0.14)$ & $0.05(0.11)$ & $0.18(0.13)$ \\
\hline Intercept & $0.03(0.07)$ & $-0.10(0.08)$ & $0.02(0.07)$ & $-0.04(0.08)$ & $-0.03(0.16)$ \\
\hline L1 Observations & 2,110 & 1,710 & 2,110 & 2,110 & 736 \\
\hline L2 Observations & 1,320 & 1,010 & 1,320 & 1,320 & 336 \\
\hline Log Likelihood & $-2,844.709$ & $-2,288.356$ & $-2,842.262$ & $-2,847.126$ & -967.931 \\
\hline A kaike Inf. Crit. & $5,721.418$ & $4,614.713$ & $5,722.523$ & $5,732.251$ & $1,973.863$ \\
\hline Bayesian Inf. Crit. & $5,811.889$ & $4,718.154$ & $5,829.958$ & $5,839.686$ & $2,061.286$ \\
\hline \multicolumn{6}{|l|}{ Variance Components } \\
\hline Level-1 SD & 0.674 & 0.668 & 0.671 & 0.674 & 0.648 \\
\hline Level-2 SD & 0.717 & 0.714 & 0.718 & 0.716 & 0.740 \\
\hline
\end{tabular}

Table A.6: Model Results for RQ3

\begin{tabular}{|c|c|c|c|}
\hline & \multicolumn{3}{|c|}{ Dependent variable: Course-Related Practices (Standardized) } \\
\hline & $\begin{array}{c}\text { Percent Schl Econ } \\
\text { Disadv }\end{array}$ & $\begin{array}{l}\text { Percent Free or } \\
\text { Reduced Lunch } \\
\text { (Z-score) }\end{array}$ & $\begin{array}{l}\text { Sch Inst Cult } \\
\text { (Z-score) }\end{array}$ \\
\hline & $(1)$ & $(2)$ & $(3)$ \\
\hline Post & $0.40^{* * *}(0.10)$ & $0.32 * * *(0.11)$ & $0.56^{* * *}(0.07)$ \\
\hline Follow-up & $0.38^{* * *}(0.12)$ & $0.35^{* *}(0.15)$ & $0.47^{* * *}(0.09)$ \\
\hline Male & $0.05(0.09)$ & $-0.07(0.15)$ & $0.09(0.10)$ \\
\hline No Bachelor's & $0.13(0.32)$ & $-2.83^{* *}(1.11)$ & $0.37(0.32)$ \\
\hline Master's g & $0.06(0.11)$ & $-0.24(0.19)$ & $-0.08(0.11)$ \\
\hline Doctoral & $0.22(0.19)$ & $-0.43(0.37)$ & $0.09(0.23)$ \\
\hline Age & $-0.003(0.005)$ & $-0.02^{* *}(0.01)$ & $0.01 *(0.01)$ \\
\hline $\mathrm{Age}^{2}$ & $0.0001(0.0004)$ & $0.001(0.001)$ & $0.0004(0.0004)$ \\
\hline Africa & $-0.32 *(0.19)$ & & $-0.01(0.20)$ \\
\hline Asia & $-0.17(0.13)$ & & $-0.03(0.13)$ \\
\hline Europe & $-0.21(0.14)$ & & $-0.04(0.15)$ \\
\hline Oceania & $0.01(0.30)$ & & $0.20(0.30)$ \\
\hline South America & $0.12(0.17)$ & & $-0.01(0.18)$ \\
\hline Schl Econ Disadv 11\%-25\% & $0.06(0.13)$ & & \\
\hline Schl Econ Disadv 26\%-50\% & $0.07(0.13)$ & & \\
\hline Schl Econ Disadv More than $50 \%$ & $-0.07(0.13)$ & & \\
\hline Schl Econ Disadv $11 \%-25 \%$ XPost & $-0.03(0.17)$ & & \\
\hline Schl Econ Disadv 11\%-25\%XFollow-up & $-0.11(0.20)$ & & \\
\hline Schl Econ Disadv 26\%-50\%XPost & $-0.32^{*}(0.17)$ & & \\
\hline Schl Econ Disadv 26\%-50\%XFollow-up & $-0.34(0.21)$ & & \\
\hline Schl Econ Disadv More than $50 \%$ XPost & $-0.29^{*}(0.17)$ & & \\
\hline Schl Econ Disadv More than $50 \%$ XFollow-up & $-0.14(0.20)$ & & \\
\hline Percent FRL (Standardized) & & $-0.15^{*}(0.08)$ & \\
\hline Percent FRL (Standardized)XPost & & $0.08(0.12)$ & \\
\hline Percent FRL (Standardized)XFollow-up & & $0.06(0.18)$ & \\
\hline Schl Inst Cult (Standardized) & & & $0.12^{* *}(0.05)$ \\
\hline Schl Inst Cult (Standardized)XPost & & & $0.08(0.08)$ \\
\hline Schl Inst Cult (Standardized)XFollow-up & & & $-0.01(0.10)$ \\
\hline Constant & $0.02(0.13)$ & $0.21(0.20)$ & $-0.13(0.12)$ \\
\hline L1 Observations & 649 & 217 & 493 \\
\hline L2 Observations & 304 & 130 & 304 \\
\hline Log Likelihood & -829.97 & -283.84 & -642.47 \\
\hline Akaike Inf. Crit. & $1,709.94$ & 595.69 & $1,322.93$ \\
\hline Bayesian Inf. Crit. & $1,821.83$ & 643.00 & $1,402.74$ \\
\hline \multicolumn{4}{|l|}{ Variance Components } \\
\hline Level-1 SD & 0.591 & 0.682 & 0.623 \\
\hline Level-2 SD & 0.703 & 00.548 & 0.674 \\
\hline
\end{tabular}




\section{References}

[1] J. Reich, J. A. Ruipérez-Valiente, The MOOC Pivot, Science 363 (6423) (2019) 130-131. doi:10.1145/3051457.3053980.

URL https://sloanc2013. wordpress . com/2013/11/21/

[2] S. Naidu, S. P. Karunanayaka, Orchestrating Shifts in Perspectives and Practices About the Design of MOOCs, in: MOOCs and Open Education in the Global South, Routledge, 2019, pp. 72-80. doi:10.4324/9780429398919-9.

[3] C. R. Glass, M. S. Shiokawa-Baklan, A. J. Saltarelli, Who Takes MOOCs?, New Directions for Institutional Research 2015 (167) (2016) 41-55. doi:10.1002/ir.20153.

URL http://doi.wiley.com/10.1002/ir.20153

[4] D. T. Seaton, C. A. Coleman, J. P. Daries, Teacher Enrollment in MIT MOOCs: Are We Educating Educators?, SSRN Electronic Journaldoi:10.2139/ssrn.2515385.

[5] G. M. Kleiman, M. A. Wolf, D. Frye, The Digital Learning Transition MOOC for Educators: Exploring a Scalable Approach to Professional Development, Tech. rep. (2013). URL http://www.mooc-ed.org/.

[6] H. Puamohala Bronson, IES Director Highlights Friday Institute MOOC-Eds in First-Year Report Friday Institute for Educational Innovation (2019).

URL https://www.fi.ncsu.edu/news/ies-director-highlights-friday-institute-mooc-eds-in-first-year-

[7] L. Bartolomé, Beyond the Methods Fetish: Toward a Humanizing Pedagogy, Harvard Educational Reviewdoi:10.17763/haer.64.2.58q5m5744t325730.

[8] D. Sanders, G. McCutcheon, The Development of Practical Theories of Teaching., Journal of Curriculum and Supervision 2 (1) (1986) 50-67.

[9] L. M. Desimone, A. C. Porter, M. S. Garet, K. S. Yoon, B. F. Birman, Effects of Professional Development on Teachers' Instruction: Results from a Three-year Longitudinal Study, Educational Evaluation and Policy Analysis 24 (2) (2002) 81-112. doi:10.3102/01623737024002081. URL http://journals. sagepub.com/doi/10.3102/01623737024002081

[10] M. A. Kraft, J. P. Papay, Can Professional Environments in Schools Promote Teacher Development? Explaining Heterogeneity in Returns to Teaching Experience., Educational evaluation and policy analysis 36 (4) (2014) 476-500. doi:10.3102/0162373713519496.

URL http://www.ncbi.nlm.nih.gov/pubmed/25866426 http://www.pubmedcentral.nih.gov/articlerender.fc

[11] A. J. Wayne, K. S. Yoon, P. Zhu, S. Cronen, M. S. Garet, Experimenting With Teacher Professional Development: Motives and Methods, Educational Researcher 37 (8) (2008) 469-479. doi:10.3102/0013189X08327154.

URL http://journals. sagepub.com/doi/10.3102/0013189x08327154

[12] H. C. Hill, Fixing Teacher Professional Development, Phi Delta Kappan 90 (7) (2009) 470-476. doi:10.1177/003172170909000705.

URL http://journals.sagepub.com/doi/10.1177/003172170909000705

[13] R. Correnti, An Empirical Investigation of Professional Development Effects on Literacy Instruction Using Daily Logs, Educational Evaluation and Policy Analysis 29 (4) (2007) 262-295. doi:10.3102/0162373707309074.

URL http://journals. sagepub.com/doi/10.3102/0162373707309074

[14] L. M. Desimone, Improving Impact Studies of Teachers' Professional Development: Toward Better Conceptualizations and Measures, Educational Researcher 38 (3) (2009) 181-199. doi:10.3102/0013189X08331140.

URL http://journals. sagepub.com/doi/10.3102/0013189x08331140

[15] M. S. Garet, A. C. Porter, L. Desimone, B. F. Birman, K. S. Yoon, What makes professional development effective? Results from a national sample of teachers, American Educational Research Journal 38 (4) (2001) 915-945. doi:10.3102/00028312038004915.

URL https://search.proquest. com/docview/200450497? accountid=12492

[16] J. P. Allen, R. C. Pianta, A. Gregory, A. Y. Mikami, J. Lun, An interaction-based approach to en- 
hancing secondary school instruction and student achievement, Science 333 (6045) (2011) 1034-1037. doi:10.1126/science.1207998.

[17] A. Y. Mikami, A. Gregory, J. P. Allen, R. C. Pianta, J. Lun, Effects of a teacher professional development intervention on peer relationships in secondary classrooms (sep 2011).

[18] S. B. Neuman, L. Cunningham, The Impact of Professional Development and Coaching on Early Language and Literacy Instructional Practices, American Educational Research Journal 46 (2) (2009) 532-566. doi:10.3102/0002831208328088.

URL http://journals. sagepub.com/doi/10.3102/0002831208328088

[19] H. C. Hill, M. Beisiegel, R. Jacob, Professional Development Research, Educational Researcher 42 (9) (2013) 476-487. doi:10.3102/0013189X13512674.

URL http://journals. sagepub.com/doi/10.3102/0013189X13512674

[20] V. D. Opfer, D. Pedder, Conceptualizing Teacher Professional Learning, Review of Educational Research 81 (3) (2011) 376-407. doi:10.3102/0034654311413609. URL http://journals. sagepub.com/doi/10.3102/0034654311413609

[21] M. Cochran-Smith, S. L. Lytle, Relationships of knowledge and practice: Teacher learning in communities, Review of Research in Education 24 (1999) 249-305. doi:10.3102/0091732x024001249.

[22] S. Loeb, D. Kalogrides, T. Béteille, Effective Schools: Teacher Hiring, Assignment, Development, and Retention, Tech. rep., National Bureau of Economic Research, Cambridge, MA (jun 2011). doi:10.3386/w17177.

URL http://www.nber.org/papers/w17177.pdf

[23] C. Dede, D. Jass Ketelhut, P. Whitehouse, L. Breit, E. M. McCloskey, A Research Agenda for Online Teacher Professional Development, Journal of Teacher Education 60 (1) (2009) 8-19. doi:10.1177/0022487108327554.

URL http://journals. sagepub.com/doi/10.1177/0022487108327554

[24] A. Lantz-Andersson, M. Lundin, N. Selwyn, Twenty years of online teacher communities: A systematic review of formally-organized and informally-developed professional learning groups (oct 2018). doi:10.1016/j.tate.2018.07.008.

[25] S. Dash, R. M. De Kramer, L. M. O'Dwyer, J. Masters, M. Russell, Impact of online professional development on teacher quality and student achievement in fifth grade mathematics, Journal of Research on Technology in Education 45 (1) (2012) 1-26. doi:10.1080/15391523.2012.10782595.

[26] T. Trust, D. G. Krutka, J. P. Carpenter, "Together we are better": Professional learning networks for teachers, Computers and Education 102 (2016) 15-34. doi:10.1016/j.compedu.2016.06.007.

[27] A. Noble, P. McQuillan, J. Littenberg-Tobias, "A lifelong classroom": Social studies educators' engagement with professional learning networks on Twitter, Journal of Technology and Teacher Education 24 (2) (2016) 187-213.

URL https://www.learntechlib.org/p/151754/

[28] J. Reich, M. Levinson, W. Johnston, Using Online Social Networks to Foster Preservice Teachers' Membership in a Networked Community of Praxis., Contemporary Issues in Technology and Teacher ... 11 (2011) 382-397.

URL https://www.learntechlib.org/p/37577/ http://www.editlib.org/p/37577

[29] D. S. Y. Choi, P. Morrison, Learning to get it right: Understanding change processes in professional development for teachers of English learners, Professional Development in Education 40 (3) (2014) 416-435. doi:10.1080/19415257.2013.806948.

[30] P. S. Dominguez, C. Nicholls, B. Storandt, Experimental Methods and Results in a Study of PBS TeacherLine Math Courses, Tech. rep. (2006).

URL www.hezel.com http://myaccess.library.utoronto.ca/login?url=http://search.proquest.com/docvie

[31] V. G. Britt, T. Paulus, "Beyond the Four Walls of My Building": A Case Study of \#Edchat as a Community of Practice, American Journal of Distance Education 30 (1) (2016) 48-59. doi:10.1080/08923647.2016.1119609.

URL https://www.tandfonline.com/action/journalInformation?journalCode=hajd20

[32] K. Brennan, S. Blum-Smith, M. M. Yurkofsky, From checklists to heuristics: Designing MOOCs to 
support teacher learning, Teachers College Record 120 (9).

[33] T. Avineri, H. S. Lee, D. Tran, J. N. Lovett, T. Gibson, Design and Impact of MOOCs for Mathematics Teachers, in: Distance Learning, E-Learning and Blended Learning in Mathematics Education: International Trends in Research and Development, 2018, pp. 185-200. doi:10.1007/978-3-319-90790-1 1 .

[34] D. Laurillard, The educational problem that MOOCs could solve: Professional development for teachers of disadvantaged students, Research in Learning Technology 24. doi:10.3402/rlt.v24.29369.

[35] P. J. Mcquillan, Small-school reform through the lens of complexity theory: It's "good to think with" (2008). URL https://eric.ed.gov/?id=EJ825747

[36] M. Cochran-Smith, F. Ell, L. Ludlow, L. Grudnoff, G. Aitken, The challenge and promise of complexity theory for teacher education research, Teachers College Record 116 (5).

URL https://eric.ed.gov/?id=EJ1020291

[37] M. Fullan, Leading in a Culture of Change By Michael Fullan, Change (2002) 1-15.

URL https://books google. com/books?hl=en\&lr=\&id=7iOKAwAAQBAJ\&oi=fnd\&pg=PR9\&dq=Fullan+2007\&ots=kfkq3kq $2007 \& f=f a l s e$

[38] J. Dewey, How we think., 2006. doi:10.1037/10903-000.

[39] D. R. Garrison, J. B. Arbaugh, Researching the community of inquiry framework: Review, issues, and future directions, Internet and Higher Education 10 (3) (2007) 157-172. doi:10.1016/j.iheduc.2007.04.001.

[40] D. R. Garrison, T. Anderson, W. Archer, Critical thinking, cognitive presence, and computer conferencing in distance education, International Journal of Phytoremediation 21 (1) (2001) 7-23. doi:10.1080/08923640109527071.

[41] C. Teddlie, A. Tashakkori, A general typology of research designs featuring mixed ethods, Research in the Schools 13 (1) (2006) 12-28. arXiv:/ehis.ebscohost.com/, doi:Article.

URL http://www.msera.org/Rits_131/Teddlie_Tashakkori_131.pdf

[42] K. J. Payne, B. J. Biddle, Poor School Funding, Child Poverty, and Mathematics Achievement, Educational Researcher 28 (6) (1999) 4-13. doi:10.3102/0013189X028006004.

URL http://journals. sagepub.com/doi/10.3102/0013189X028006004

[43] S. R. Sirin, Socioeconomic Status and Academic Achievement: A Meta-Analytic Review of Research, Review of Educational Research 75 (3) (2005) 417-453. doi:10.3102/00346543075003417. URL http://journals. sagepub.com/doi/10.3102/00346543075003417

[44] L. M. Hopson, E. Lee, Mitigating the effect of family poverty on academic and behavioral outcomes: The role of school climate in middle and high school, Children and Youth Services Review 33 (11) (2011) 2221-2229. doi:10.1016/j.childyouth.2011.07.006.

[45] M. O. Martin, I. V. S. Mullis, P. Foy, G. M. Stanco, International Association for the Evaluation of Educational Achievement., Trends in International Mathematics and Science Study., TIMSS 2011 international results in science, 2013.

[46] U. States Department of Agriculture, The National School Lunch Program, Tech. rep. (2017). URL http://www.fns.usda.gov/tn/team-nutrition.

[47] S. Raudenbush, A. Bryk, Hierarchical Linear Models: Applications and Data Analysis Methods - Stephen W. Raudenbush, Anthony S. Bryk - Google Books, 2nd Edition, Sage Publications, 2002.

URL https://books . google. com/books?hl=en\&lr=\&id=uyCVOCNGDLQC\&oi=fnd\&pg=PR17\&dq=raudenbush+bryk\&ots=qB bryk\&f $=f a l s e$

[48] D. Bates, M. Mächler, B. M. Bolker, S. C. Walker, Fitting linear mixed-effects models using lme4, Journal of Statistical SoftwarearXiv:1406.5823, doi:10.18637/jss.v067.i01.

[49] M. Harwell, B. LeBeau, Student Eligibility for a Free Lunch as an SES Measure in Education Research, Educational Researcher 39 (2) (2010) 120-131. doi:10.3102/0013189X10362578.

URL http://journals.sagepub.com/doi/10.3102/0013189X10362578

[50] T. Trust, New Model of Teacher Learning in an Online Network, Journal of Research on Technology in Education 48 (4) (2016) 290-305. doi:10.1080/15391523.2016.1215169. 